\title{
Diethylstilbestrol Action on Leydig Cell Function and Testicular Descent
}

\author{
Christopher R. Cederroth and Serge Nef
}

\begin{abstract}
Exposure to environmental chemicals may adversely affect the endocrine system and male sexual development. Testicular descent is regulated hormonally by Leydig-cell derived testosterone and Insulin-like factor 3 (Ins/3). While Ins 3 is required for transabdominal descent by stimulating the contraction and growth of the gubernaculum, testosterone contributes to the involution of the suspensory ligament and mediates the inguinoscrotal phase of the descent. In rodents, prenatal exposure to estradiol or xenoestrogens such as diethylstilbestrol (DES) leads to cryptorchidism and is associated with a downregulation of Insl3 transcription. In this review, we summarize the molecular and endocrine events responsible for testicular descent and how fetal exposure to xenoestrogens can adversely affect it. Recent data suggest that in utero exposure to DES affects fetal Leydig cell endocrine functions, more precisely the steroidogenic function, Insl3 expression and testicular descent, via an ER $\alpha$-dependent mechanism. The expression of Leydig-specific genes such as Insl3, Cyp17a1, Star and Renin1 were profoundly decreased upon exposure to E2 or DES but not affected in mutant testes lacking ER $\alpha$. Whether these effects of ER $\alpha$ are mediated via its classical mode of action or through a non-genomic action remains unclear. Unraveling the molecular events inhibiting the endocrine functions of fetal Leydig cells through an ER $\alpha$-dependent mechanism will provide important insights into the adverse effects of estrogenic exposure on the male urogenital system and testicular descent.
\end{abstract}

Keywords: Cryptorchidism · Endocrine disruptors · Expression profiling · Gene regulation · Testis · Uterus

\section{Human Male Reproductive Health Disorders}

Clinical and epidemiological studies published since the 1980s have indicated a drastic increase in the incidence of male reproductive health problems. These disorders include cryptorchidism (undescended testes), ${ }^{[1]}$ hypospadias, ${ }^{[2]}$ declining semen quality ${ }^{[3]}$ and testicular cancer, ${ }^{[4]}$ all of which are grouped under the term Testicular Dysgenesis Syndrome (TDS). The rapid increase of TDS over the past 50 years suggests that environmental or lifestyle factors and not genetic factors are most likely involved in

${ }^{\star}$ Correspondence: Prof. Dr. S. Nef

Department of Genetic Medicine and Development

University of Geneva Medical School

$\mathrm{CH}-1211$ Geneva 4

E-mail: Serge.Nef@medecine.unige.ch. these changes in male reproductive health Furthermore, basic, clinical and epidemiological studies have come to a consensus in suggesting that the underlying causes of human male reproductive disorders operate in the fetus (for a review see Norgil Damgaard et $\left.a l^{[5]}\right)$. This seems logical since testicular descent, closure of the urethra along the shaft of the penis (the failure of which causes hypospadias), testicular development and differentiation all occur during fetal life.

\section{Endocrine Disruptors and Xenoestrogens}

Any chemical with the ability to interfere with, mimic or antagonize the function and/ or the production of testicular hormones may cause adverse effects by disrupting testicular function and subsequent reproductive organ development. Such molecular compounds are called endocrine disruptors (EDs) and are defined by the European Commission as "exogenous substances that alter function(s) of the endocrine system and, as a consequence, cause adverse health effects in an intact organism". Xenoestrogens are one particular class of EDs characterized by their estrogenic activity. These estrogenic compounds are part of our daily environment since they are found in numerous human-made or natural products such as in pesticides (e.g. DDT derivatives, methoxychlor, kepone), in products associated with plastics (e.g. bisphenol-A, nonylphenol), in pharmaceutical agents (e.g. DES, tamoxifen, raloxifen), in ordinary household products (breakdown products of detergents and surfactants), in industrial chemicals (PCBs), in UV filters (e.g. 4-methylbenzylidene camphor (4-MBC) and octocrylene (OC)) as well as in food (phytoestrogens such as genistein, daidzein). Among these, diethylstilbestrol (DES), a synthetic estrogen, stands apart since it was the first and remains the best-characterized endocrine disruptor. DES was prescribed to more than 5 million pregnant women from the late 1940 s to early 1970 s to prevent abortion, pre-eclampsia and other pregnancy complications (for review see Jensen $e t$ al. $\left.{ }^{[6]}\right)$. Daughters of women treated with the drug during pregnancy have a higher risk of developing clear cell adenocarcinoma of the vagina, while male children exposed in utero to DES have a higher risk of developing the symptoms of TDS. ${ }^{[7,8]}$

\section{Male Sexual Development}

Male sexual differentiation requires the synthesis and the secretion of three testicular hormones: testosterone, Müllerian inhibit- 
ing substance (MIS) and insulin-like factor 3 (Insl3). MIS, secreted by Sertoli cells, promotes the regression of the Müllerian ducts. Without MIS, the Müllerian ducts would develop and ultimately give rise to the uterus, the oviduct and the upper part of the vagina. Testosterone, synthesized by Leydig cells, directs the differentiation of male accessory organs including the vas deferens, the seminal vesicles, the second phase of testicular descent and the development of the external male genitalia. Finally, Insl3, also produced by Leydig cells, mediates the first phase of testicular descent. Interference with the production or action of these three sexual hormones by EDs during gonadal development can disrupt the sexual differentiation of the male fetus.

\section{Testicular Descent Occurs in Two Hormonally Controlled Phases}

Testicular descent is an important aspect of male sexual development. Failure of the testes to descend into the scrotum (cryptorchidism) is one of the most common birth defects in humans affecting approximately $2-3 \%$ of newborn males. Because intraabdominal temperature is toxic for male germ cells, cryptorchidism often results in infertility and increases the risk of testicular cancer. ${ }^{[9]}$

Gonadal positioning relies on the development of two ligaments that connect the gonad to the abdominal wall: the cranial ligament known as the cranial suspensory ligament (CSL) and the caudal ligament named the gubernaculum, a mesenchymal tissue that connects the developing gonad to the inguinal abdominal wall. In males, outgrowth of the gubernaculum and regression of the CSL descends the testis transabdominally whereas in females, development of the CSL and developmental failure of the gubernaculum positions the ovaries next to the kidneys (Fig. 1A).

Hormonal control of testicular descent occurs in two steps: the transabdominal phase and the inguinoscrotal phase. ${ }^{9,10]}$ The transabdominal phase (from E15.5 to E17.5 in mice) relocates the testes from a high abdominal position to the base of the abdomen, close to the inguinal canal. This process is mediated by androgens and Insl3. Testosterone triggers the regression of the CSL, and Insl3 acts on the gubernaculum through the binding to its receptor LGR8 to promote its outgrowth and contraction. The second phase involves the movement of the testes from the base of the abdomen to the scrotum and is mediated by androgens (for a review see Nef and Parada ${ }^{[11]}$ ). In females, the absence of testosterone and Insl 3 enables the CSL to develop and maintain the ovaries next to the kidneys, while the gubernaculum remains thin and elongated.

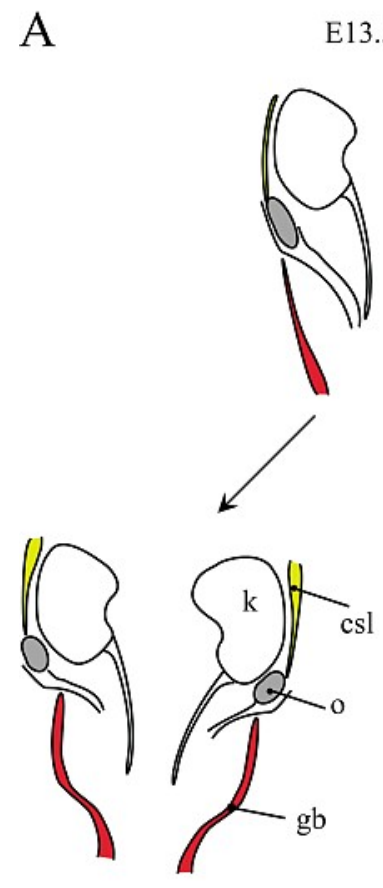

E17.5 female
13.5 Embryo

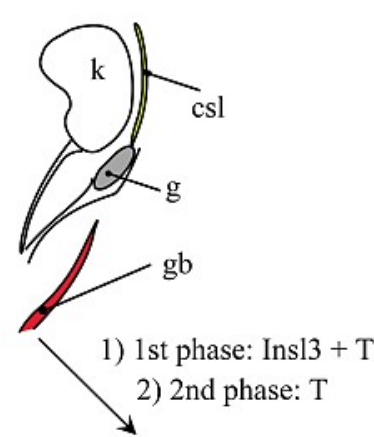

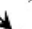
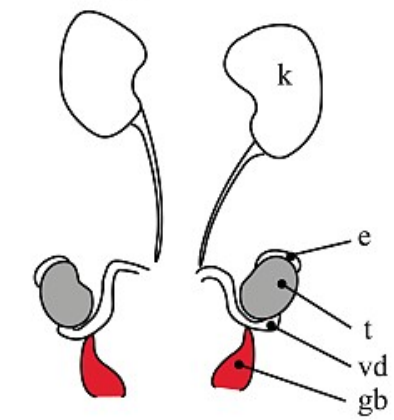

E17.5 male
B

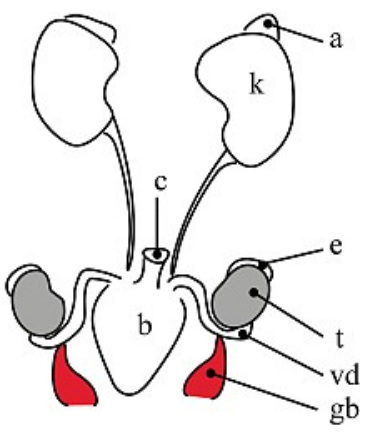

E2 or DES treated

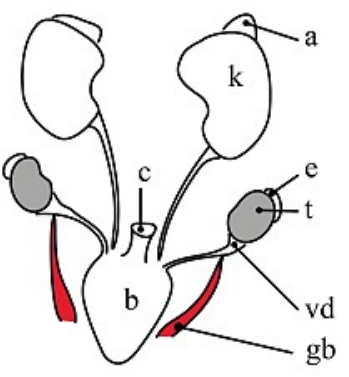

Fig. 1. (A) Schematic drawing describing the first phase of testicular descent in mice. In males, the presence of testosterone induces regression of the cranial suspensory ligaments (CSL), while InsI3 promotes the contraction of gubernacular cords and outgrowth of gubernacular bulbs. These morphological changes in the genital ligaments allow the testes to relocate at the base of the abdominal cavity. In females, the absence of testosterone allows the CSL to develop and retain the ovaries at their original position, while the gubernaculum elongates and does not develop because of the absence of InsI3. (B) Schematic drawing of testicular positioning at E18.5 under normal conditions or after in utero exposure to xenoestrogens. At this stage, the transabdominal descent is completed and the testes are located at the level of the bladder neck, and the gubernaculum is contracted and well developed. Estrogen exposure induces cryptorchidism characterized by intra-abdominal testes usually located below the kidneys and a thin elongated gubernaculum. Legend: adrenal (a), kidney (k), coecum (c), cranial suspensory ligament (csl), ovary (o), gonad (g), bladder (b), epidydima (e), testis $(\mathrm{t})$, vas deferens $(\mathrm{vd})$, gubernaculum $\left(\mathrm{gb}-\right.$ in red). Modified from Nef et al. ${ }^{[11]}$

\section{Insulin like-3: An Essential Hormone for Gonadal Positioning}

The evidence that Insl3 plays a role in testicular descent came from the generation of mice lacking Insl3 or its receptor LGR8. These mice were found to exhibit bilateral cryptorchidism, abnormal gubernacular development, spermatogenesis defects, and infertility. ${ }^{[12,13]}$ The insulin like-3 gene, also known as Leydig insulin-like hormone (Ley $\mathrm{I}-\mathrm{L}$ ), or relaxin-like factor (RLF), is a member of the insulin family which includes insulin, relaxin, and insulin-like growth factors I and II. Like insulin, the mature Insl3 peptide is composed of $\mathrm{A}$ and $\mathrm{B}$-chains linked by disulfide bonds ${ }^{[14]}$ and binds to its receptor LGR8 which is a member of leucinerich repeat-containing G-protein coupled receptor family. ${ }^{[15]}$ Insl3 expression during sex determination is sexually dimorphic. ${ }^{[16]}$ In male mice, Insl3 transcripts are first detected at E13.5 in fetal Leydig cells. Its expression remains constant up until postnatal $(\mathrm{P})$ day 3-5 where a slight decrease is observed. Post-natal transcript levels of Insl3 increase again as fetal Leydig cells are replaced by mature Leydig cells and reach the highest levels in adult testis. Insl3 gene regulation appears to be regulated differently in fetal and adult population of Leydig cells. In fetal Leydig cells, Insl3 gene expression occurs independently of the hypothalamopituitary-gonadal (HPG) axis and is inhibited by estrogenic compounds such as estradiol or DES. In mature Leydig cells in contrast, Insl3 gene expression is under the control of the HPG axis ${ }^{[17,18]}$ but unaffected by estrogens. ${ }^{[19]}$ For example, in hpg mutant mice that lack a functional HPG axis, Insl3 expression is unaffected in fetal Leydig cells whereas it is fairly absent in mature Leydig cells, suggesting that only postnatal transcription of Insl3 requires signals from the CNS. ${ }^{[17]}$ Confirming this hypothesis, mice lacking the LH-receptor (LhRKO) display normal transabdominal descent but postnatal bilateral cryptorchidism with impaired inguinoscrotal descent which is rescued by testosterone treatment. ${ }^{[18]}$ Thus, the expres- 
sion of Insl3 in fetal Leydig cells is crucial for transabdominal descent and development of the gubernaculum.

\section{Xenoestrogens and Cryptorchidism}

Ins13 and LGR8 appear to play similar roles in human sexual development, although mutations in these genes are not a common cause of cryptorchidism in humans. ${ }^{[20]}$ Still, cryptorchidism has been associated with mutations in the Ins13 or LGR8 loci. ${ }^{[12]}$ Since $90 \%$ of cryptorchidism cases are spontaneous, it would seem that environmental factors, rather than genetic factors, are the most plausible cause. Abnormal estrogen action has been hypothesized to be a possible cause for sporadic cryptorchidism in humans. For instance, treatment of pregnant women with DES is associated with undescended testis in male offspring. ${ }^{[7]}$ A clinical study showed that mothers of cryptorchid children had higher levels of free estradiol during the first trimester as compared to mothers whose offspring had normally descended testes. ${ }^{[21]} \mathrm{Fi}-$ nally, Hadziselimovic et al. ${ }^{[22]}$ demonstrated an increased expression of estradiol in placenta of boys with cryptorchid testes.

Animal studies support the observations in humans. Indeed, for many years the main experimental model for intra-abdominal cryptorchidism was obtained by exposure of pregnant mice to exogenous estrogens. ${ }^{[23]}$ The effects of estradiol include a reduction of gubernacular outgrowth, the induction of estrogen receptors within the Wolffian ducts, and the stabilization of the Müllerian ducts. In mice, in utero exposure to estradiol or DES induces cryptorchidism (Fig. 1B) in association with a severe downregulation of Insl3 transcription. ${ }^{[19,24]}$ Similarly, gestational exposure to phthalate esters, an endocrine disruptor with weak estrogenic activities, also impairs Insl3 gene expression and the transabdominal phase of testicular descent in rat embryos. ${ }^{[25]}$

\section{Transcriptome Analysis of Testes from Embryos Exposed to E2 or DES}

In order to identify the molecular mechanisms implicated in xenoestrogen-dependant cryptorchidism, we have characterized the transcriptional changes in the fetal testis after exposure to E2 (6 mg, single I.P. injection) and DES (10 $\mu \mathrm{g} /$ day, osmotic pump delivery). Our expression profiling analysis indicated that 6 and 31 genes are respectively down-regulated and up-regulated ( $>4$ fold change) by estrogen exposure in utero. ${ }^{[26]}$ Amongst the genes whose transcription is inhibited by both E2 and DES, we found four which are specifically expressed in Leydig cells (i.e. Ins13, Steroidogenic acute regulatory protein (Star), Cytochrome p450
17 $\alpha$-hydroxylase/17-20-lyase (Cyp17a1) and Renin). Genes expressed specifically in Sertoli cells (i.e. Müllerian Inhibiting Substance (MIS)) and in the germ cell lineage (e.g. Oct4) are not affected by xenoestrogen exposure in utero. In vitro studies have shown that Insl3 transcription is regulated by Sf-1 and its cofactor Dax, ${ }^{[27,28]}$ a negative regulator of transcription. Sf-1 and Dax-1 transcription were not affected by E2 or DES, excluding possible effects on the transcription of these genes as mediator of estrogen action on Insl3 transcription. On the other hand, Star and Cyp17a1 were already known to be targets of estrogens after fetal exposure. [24,29] Both genes are crucial for the synthesis of testosterone. Star is the rate limiting enzyme for steroidogenesis by regulating cholesterol transport into the inner membrane of the mitochondria. Mice lacking the Star gene display male to female phenotypic sex reversal and have impaired inguinoscrotal descent of the testis due to the absence of androgen production. ${ }^{[30]}$ Cyp17a1 is an enzyme that is part of the steroidogenic cascade but the proof of its essential function in testis steroid synthesis has never been shown since mice lacking Cyp17a1 die at E7.5, before gastrulation. ${ }^{[31]}$ Thus disruption of Star and Cyp17a1 expression is consistent with lower androgen production. Amongst the probe sets that are upregulated, we found genes implicated in cancer, metabolism, bone formation and cell architecture, but no gene with testicular function has been found.

Interestingly, we found that Star expression is not down-regulated by E2 or DES in the fetal adrenal gland. In this organ, the levels of ER $\alpha$ and ER $\beta$ transcripts were low in comparison with the fetal testis, suggesting that ERs may play a role. Since ER $\beta$ inacti-

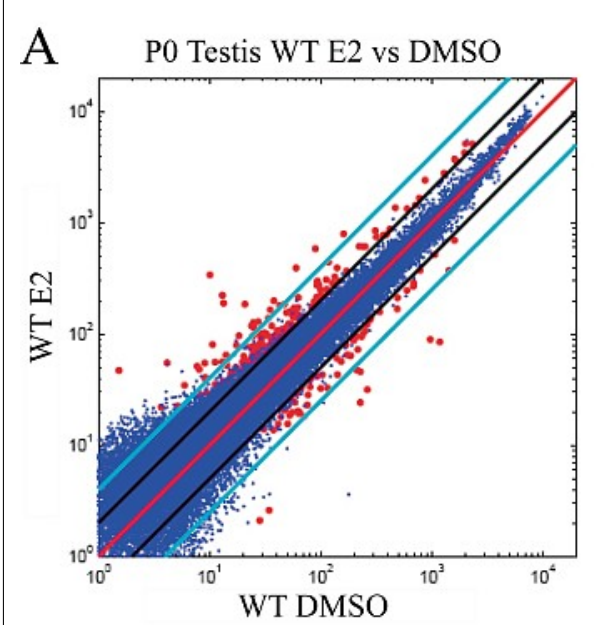

B

vation has no consequence on the endocrine functions of the fetal Leydig cells, ${ }^{[32,33]}$ these results suggested that $\mathrm{ER} \alpha$ was responsible for the estrogen-dependant downregulation of endocrine genes in the testis.

\section{ER $\alpha$ Mediates DES-induced Cryptorchidism and Testis Dysgenesis}

This hypothesis has been tested by exposing ER $\alpha \mathrm{KO}$ embryos to E2 and DES and analyzing the transcriptome profile of the fetal testis. As depicted on the scatterplot (Fig. 2 ), in ER $\alpha \mathrm{KO}$ testis, very few genes are affected by estrogen exposure, suggesting that ER $\alpha$ plays a major role during fetal exposure to E2 or DES. We found that all genes downregulated when exposed to estradiol or DES have their expression restored in absence of $\mathrm{ER} \alpha$ (Fig. 3). Concerning the genes that are upregulated, two-thirds were overexpressed in absence of ER $\alpha$ because of either (i) an $E R \alpha$-independent mechanism, (ii) the absence of ER $\alpha$ itself, or (iii) E2 toxicity.

In contrast to ER $\alpha$ mutant mice, testicular descent in both wild type and ER $\beta$ mutant mice was impaired by in utero exposure to E2 or DES. This indicates that ER $\alpha$, but not ER $\beta$, mediates estrogen-dependent inhibition of the endocrine functions of fetal Leydig cells. In ER $\alpha$ mutant mice, testicular descent appeared normal, the gubernaculum was contracted and developed even in the presence of very high levels of exogenous estrogens (Fig. 4). In addition, Insl3 transcription is fully restored in absence of $\mathrm{ER} \alpha$, but not in absence of ER $\beta$ even in presence of saturating levels of exogenous estrogens, indicating that $\mathrm{ER} \alpha$ mediates Insl3 down-

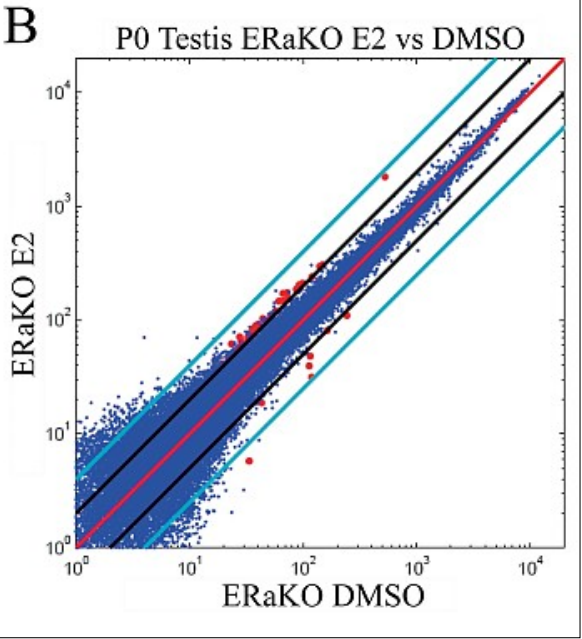

Fig. 2. Global expression analysis of the transcriptomes of WT or ER $\alpha$ mutant testes exposed to $17 \beta$ estradiol. Scatter plot analysis representing the systematic comparison of the log2-scaled expression signals from WT (A) or ER $\alpha$ mutant $(B)$ testes exposed in utero to E2 or DMSO. Blue dots represent genes with expression levels statistically similar in both conditions, while red dots represent genes whose expression profiles were found to be affected by E2 exposure ( $\geq 2$ - and $\geq 4$-fold change, black and blue diagonals respectively). Reprinted with the permission of Endocrinology see Cederroth et al. [26] 


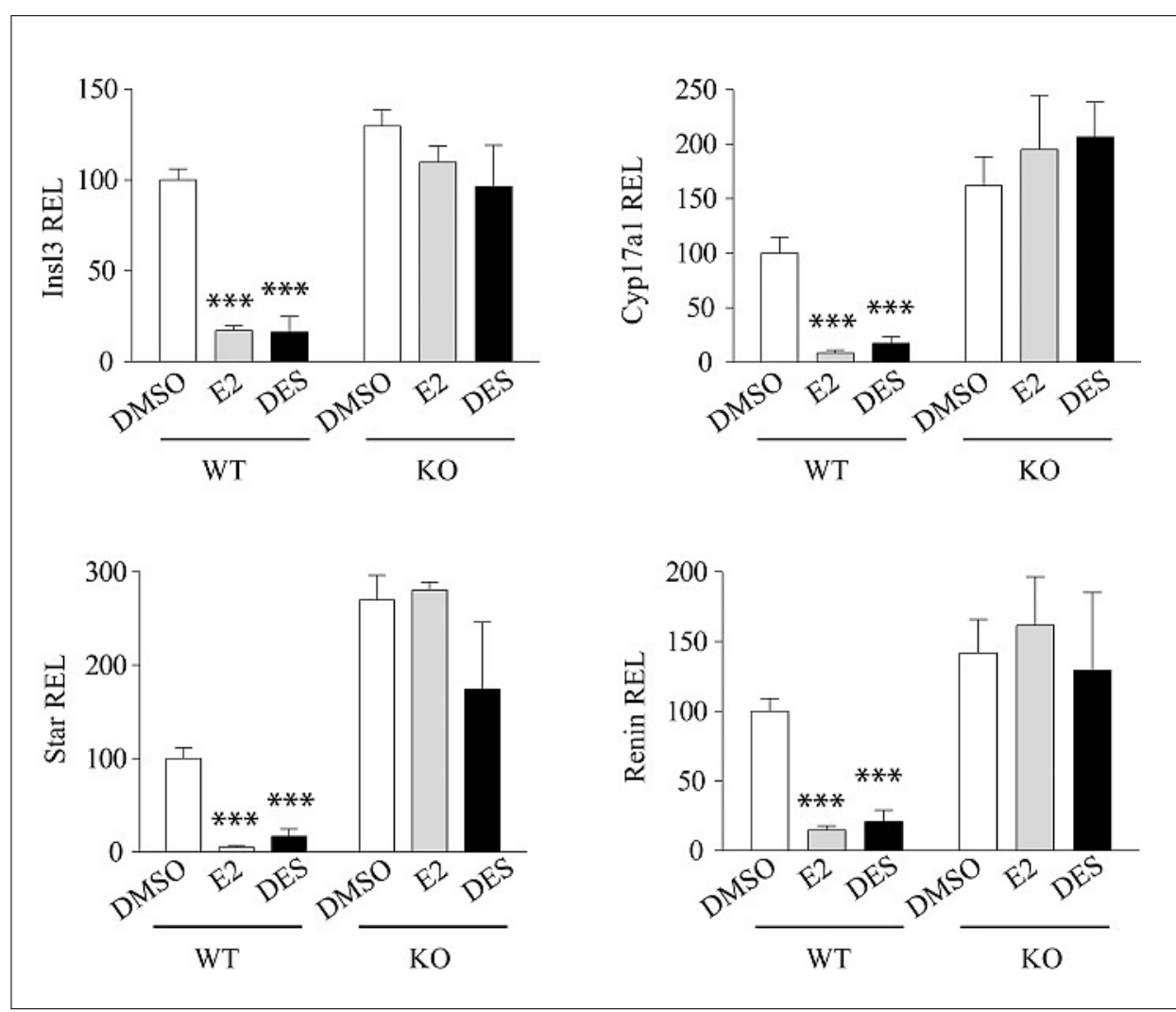

Fig. 3. Quantitative RT-PCR using WT and ER $\alpha$ mutant testes as template. Messenger RNA expression levels of representative genes modulated by in utero exposure to E2 and DES in WT and ER $\alpha$ mutant testes. White bars represent control (DMSO-treated) animals while gray and black bars symbolize E2 and DES exposed animals. Results are mean \pm SEM ( $n=3$ /group), ${ }^{\star} p<0.05,{ }^{\star \star} p<0.01,{ }^{\star \star *} p<0.001$ versus DMSO. Reprinted with the permission of Endocrinology see Cederroth et al. ${ }^{[26]}$

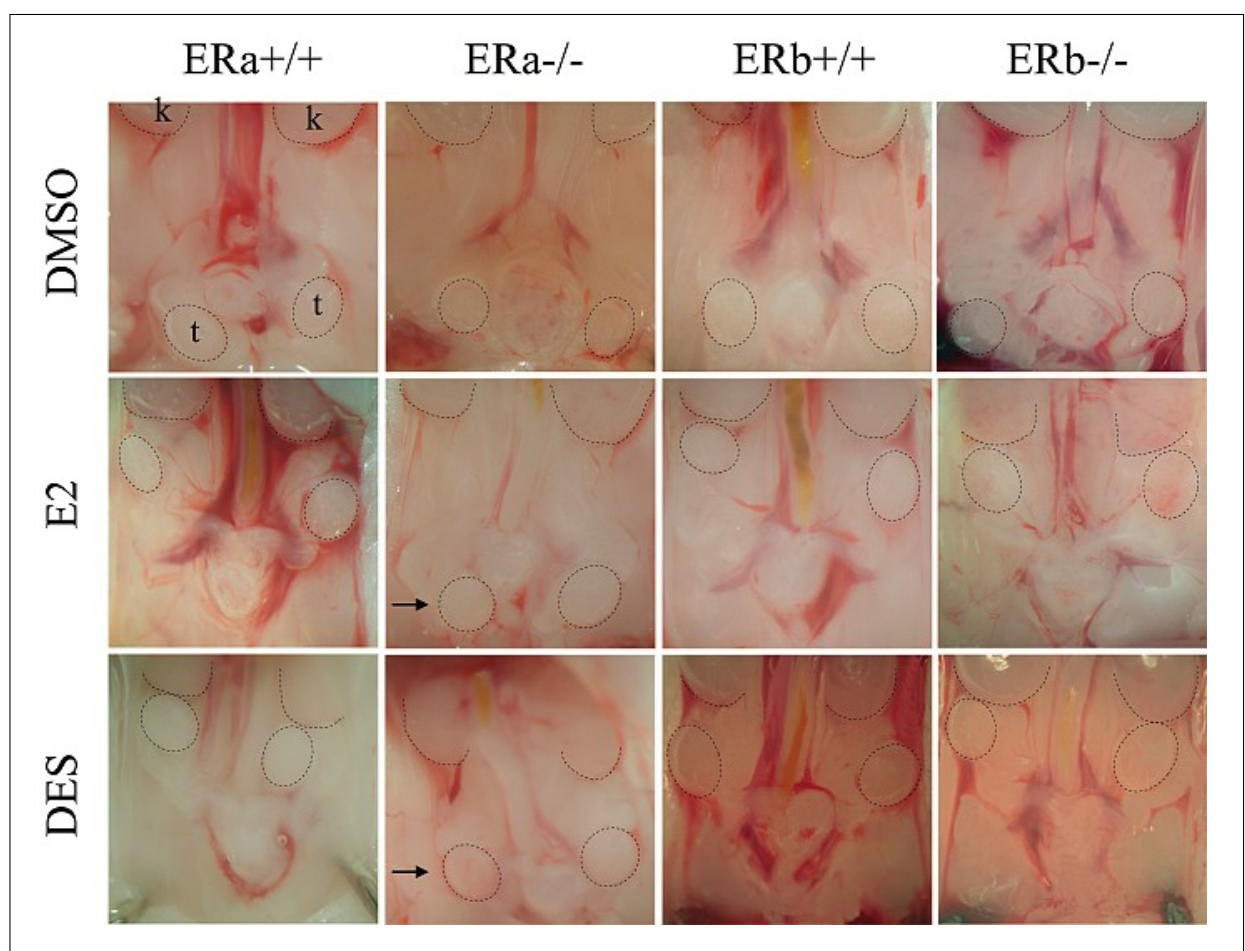

Fig. 4. Normal testicular descent in mice lacking $E R \alpha$ but not ER $\beta$ exposed to E2 or DES. Photomicrographs of the urogenital system of E18.5 embryos exposed to E2, DES or vehicle (DMSO) and that are mutant for $\mathrm{ER} \alpha$ or $\mathrm{ER} \beta$. Note that the transabdominal descent is completed only in $\mathrm{ER} \alpha$ mutant animals despite exposure to E2 or DES (arrows). The bladder has been surgically removed to ensure better accessibility and the position of the testes and kidneys have been encircled with dashed lines for better visibility. Legend: kidney $(k)$, testis $(t)$. Reprinted with the permission of Endocrinology see Cederroth et al. ${ }^{[26]}$ regulation and subsequent cryptorchidism upon exposure to xenoestrogens in utero.

\section{Mechanisms of Estrogen Action}

Previous studies support a direct effect of xenoestrogens on fetal Leydig cells. ${ }^{[32,34]}$ Our own studies demonstrate a critical role for $\mathrm{ER} \alpha$ in this effect. However, the mechanism regulating ER $\alpha$-dependent down-regulation of Insl3 and steroidogenic genes remains unclear. It is possible that estrogen-activated $\mathrm{ER} \alpha$ binds directly to estrogen regulatory elements (ERE) or other non-ERE binding sites (e.g. SF-1 response element, SFRE) in target genes via a classical mode of action and induces changes in gene expression. ${ }^{[27]}$ So far, no experimental data indicate that $\mathrm{ER} \alpha$ may act directly, through ERE or SFRE, on the promoter of Insl3. Analysis of the $190 \mathrm{bp}$ Ins13 proximal promoter required for Leydig cell-specific transcription did not reveal any putative EREs ${ }^{[27,28]}$ and electromobility shift assays (EMSA) performed with in vitro translated ER $\alpha$ or ER $\beta$ failed to show that these receptors interact with the Insl3 $190 \mathrm{bp}$ promoter. ${ }^{[26]}$ Alternatively, DES-dependent cryptorchidism may be mediated through a non-genomic pathway involving a crosstalk between ER $\alpha$ and unknown cellular signaling pathways. It has been reported that E2 induces rapid responses through pathways that involve $\mathrm{ER} \alpha, \mathrm{c}-\mathrm{Src}$ tyrosine kinases and mitogen activated protein kinases (MAPK). [35] These rapid pathways are activated not only by estrogen but also by endocrine disruptors such as BPA. ${ }^{[36]}$ It has been recently shown that estrogen actions on breast cancer cells require the insulin like growth factor-1 receptor (IGF-1R)/MAPK pathway. In cholinergic neurons, inhibition of MAPK blocks estrogen-dependant cAMP element-binding protein (CREB) phosphorylation ${ }^{[37]}$ and in cortical neurons, PI3K inhibitors inhibit estrogen activation of Akt and ERK. ${ }^{[38]}$ The crosstalk between estrogen and insulin pathways may be more important than expected and future studies should investigate the implications of the insulin pathways in mediating fetal actions of xenoestrogens.

\section{Discussion}

Most probably no single compound with endocrine-disrupting activities is the culprit of cryptorchidism, but additive effects of a mixture of EDs in utero may contribute to testicular maldescent. In addition, variation in the severity of xenoestrogen-induced cryptorchidism may be related to animal models, genetic influences, dose-dependant effects and/or epigenetic changes. For instance, rats exposed in utero the phtalate esters exhibit cryptorchidism and reduced Insl3 gene expression, ${ }^{[25]}$ whereas, no effects on cryp- 
torchidism and Insl3 transcription could be observed in mice at similar doses of phtalates (personal data). Even between different strains of mice, the genetic background could influence the susceptibility to EDs: for example it has been shown that CD-1 outbred mice are 16 times more sensitive to the disruptive effects of estradiol on spermatogenesis than inbred strains such as the C57/B6J.[39] Fetal exposure to endocrine disruptors such as BPA or DES at parts-per-billion (ppb) (equivalent to $20 \mathrm{ng} / \mathrm{kg} /$ day) has irreversible effects on the reproductive organs. ${ }^{[40]}$ The fact that very small doses may have severe effects in rodents causes a lot of attention among the scientific community and is crucial for risk assessment. ${ }^{[41]}$ To our knowledge, effects of fetal exposure to such low doses of DES on cryptorchidism are lacking. We found that exposure to DES doses in the range of $8 \mu \mathrm{g} /$ $\mathrm{kg}$ /day during gestation was not sufficient to adversely affect testicular descent and Insl3 transcription although we do not exclude a potential effect at ppb doses. Finally, the increased frequency in reproductive disorders may include transgenerational effects. Gestational exposure to EDs has been reported to induce epigenetic changes ${ }^{[42]}$ that can permanently affect male fertility through several generations. ${ }^{[43]}$ While data demonstrating the adverse effects of EDs on human reproductive function are sparse, the homology in reproductive system and endocrine regulations between animal models and humans indicates a potential for detrimental effects on testicular endocrine function and cryptorchidism.

\section{Acknowledgments}

We thank Prof. J.-D. Vassalli for critical comments on the manuscript. Authors were funded by grants from the Swiss National Science Foundation (NRP50 4050-104375) and the Cloëtta foundation. We apologize to other scientific colleagues whose work could not be cited due to space limitations.

Received: March 22, 2008

[1] a) C. Chilvers, M. C. Pike, D. Forman, K. Fogelman, M. E. Wadsworth, Lancet 1984, 2, 330; b) D. M. Campbell, J. A. Webb, T. B. Hargreave, Br. Med. J. (Clin. Res. Ed.) 1987, 295, 1235.

[2] P. Matlai, V. Beral, Lancet 1985, 1, 108

[3] a) S. Irvine, E. Cawood, D. Richardson, E. MacDonald, J. Aitken, Br. Med. J. 1996, 312, 467; b) A. G. Andersen, T. K. Jensen, E. Carlsen, N. Jorgensen, A. M. Andersson, T. Krarup, N. Keiding, N. E. Skakkebaek, Hum. Reprod. 2000, 15, 366.

[4] a) H. O. Adami, R. Bergstrom, M. Mohner, W. Zatonski, H. Storm, A. Ekbom, S. Tretli, L. Teppo, H. Ziegler, M. Rahu, et al., Int. J. Cancer 1994, 59, 33; b) H. Moller, D. Cortes, G. Engholm, J. Thorup, Br. Med. J. 1998, 317, 729.

[5] I. Norgil Damgaard, K. M. Main, J. Toppari, N. E. Skakkebaek, Best Pract. Res. Clin. Endocrinol. Metab. 2002, 16, 289.
[6] T. K. Jensen, J. Toppari, N. Keiding, N. E. Skakkebaek, Clin. Chem. 1995, 41, 1896.

[7] W. B. Gill, G. F. Schumacher, M. Bibbo, F H. Straus, 2nd, H. W. Schoenberg, J. Urol. 1979, 122, 36 .

[8] a) A. L. Herbst, R. E. Scully, S. J. Robboy, Natl. Cancer Inst. Monogr. 1979, 25; b) A. L. Herbst, H. Ulfelder, D. C. Poskanzer, N. Engl. J. Med. 1971, 284, 878; c) A. J. Wilcox, D. D. Baird, C. R. Weinberg, P P. Hornsby, A. L. Herbst, N. Engl. J. Med. 1995, 332, 1411

[9] J. M. Hutson, M. Baker, M. Terada, B. Zhou, G. Paxton, Reprod. Fertil. Dev. 1994 6,151 .

[10] a) J. M. Hutson, Lancet 1985, 2, 419; b) I. Satokata, G. Benson, R. Maas, Nature 1995, 374, 460 .

[11] S. Nef, L. F. Parada, Genes Dev. 2000, 14, 3075.

[12] a) N. V. Bogatcheva, A. Ferlin, S. Feng, A. Truong, L. Gianesello, C. Foresta, A. I. Agoulnik, Am. J. Physiol. Endocrinol. Metab. 2007, 292, E138; b) I. P. Gorlov, A. Kamat, N. V. Bogatcheva, E. Jones, D. J. Lamb, A. Truong, C. E. Bishop, K. McElreavey, A. I. Agoulnik, Hum. Mol. Genet. 2002, 11, 2309.

[13] a) S. Nef, L. F. Parada, Nat. Genet. 1999, 22 295; b) S. Zimmermann, G. Steding, J. M. Emmen, A. O. Brinkmann, K. Nayernia, A F. Holstein, W. Engel, I. M. Adham, Mol. Endocrinol. 1999, 13, 681.

[14] I. M. Adham, E. Burkhardt, M. Benahmed, W. Engel, J. Biol. Chem. 1993, 268, 26668.

[15] J. Kumagai, S. Y. Hsu, H. Matsumi, J. S Roh, P. Fu, J. D. Wade, R. A. Bathgate, A. J. Hsueh, J. Biol. Chem. 2002, 277, 31283

[16] a) S. Zimmermann, P. Schottler, W. Engel, I. M. Adham, Mol. Reprod. Dev. 1997, 47 , 30; b) S. Nef, O. Schaad, N. R. Stallings, C. R. Cederroth, J. L. Pitetti, G. Schaer, S. Malki, M. Dubois-Dauphin, B. BoizetBonhoure, P. Descombes, K. L. Parker, J. D. Vassalli, Dev. Biol. 2005, 287, 361.

[17] M. Balvers, A. N. Spiess, R. Domagalski, N. Hunt, E. Kilic, A. K. Mukhopadhyay, E. Hanks, H. M. Charlton, R. Ivell, Endocrinology 1998, 139, 2960.

[18] a) T. Klonisch, P. A. Fowler, S. HombachKlonisch, Dev. Biol. 2004, 270, 1; b) F. P. Yuan, D. X. Lin, C. V. Rao, Z. M. Lei, Hum. Reprod. 2006, 21, 936.

[19] S. Nef, T. Shipman, L. F. Parada, Dev. Biol. 2000, 224, 354.

[20] L. A. Baker, S. Nef, M. T. Nguyen, R. Stapleton, A. Nordenskjold, H. Pohl, L. F. Parada, J. Urol. 2002, 167, 2534.

[21] L. Bernstein, M. C. Pike, R. H. Depue, R. K. Ross, J. W. Moore, B. E. Henderson, B $r$ J. Cancer 1988, 58, 379.

[22] F. Hadziselimovic, R. Geneto, L. R. Emmons, J. Urol. 2000, 164, 1694

[23] a) C. A. Grocock, H. M. Charlton, M. C. Pike, J. Reprod. Fertil. 1988, 83, 295; b) C. Perez-Martinez, M. J. Garcia-Iglesias, M. C. Ferreras-Estrada, A. M. BravoMoral, J. Espinosa-Alvarez, A. EscuderoDiez, J. Comp. Pathol. 1996, 114, 407; c) F. Hadziselimovic, J. Girard, Horm. Res. 1977, 8, 76 .

[24] J. M. Emmen, A. McLuskey, I. M. Adham, W. Engel, M. Verhoef-Post, A. P. Themmen, J. A. Grootegoed, A. O. Brinkmann, Endocrinology 2000, 141, 846.
[25] a) T. Shono, Y. Shima, T. Kondo, S. Suita, J. Pediatr. Surg. 2005, 40, 1861; b) V. S. Wilson, C. Lambright, J. Furr, J. Ostby, C. Wood, G. Held, L. E. Gray, Jr., Toxicol. Lett. 2004, 146, 207.

[26] C. R. Cederroth, O. Schaad, P. Descombes, P. Chambon, J. D. Vassalli, S. Nef, Endocrinology 2007, 148, 5507.

[27] P. Koskimies, J. Levallet, P. Sipila, I Huhtaniemi, M. Poutanen, Endocrinology 2002, 143, 909.

[28] S. Zimmermann, A. Schwarzler, S. Buth, W. Engel, I. M. Adham, Mol. Endocrinol. 1998, 12,706 .

[29] a) R. Guyot, F. Odet, P. Leduque, M. G. Forest, B. Le Magueresse-Battistoni, Mol. Cell Endocrinol. 2004, 220, 67; b) G. Majdic, R. M. Sharpe, P. J. O'Shaughnessy, P. T. Saunders, Endocrinology 1996, 137, 1063.

[30] a) T. Hasegawa, L. Zhao, K. M. Caron, G. Majdic, T. Suzuki, S. Shizawa, H. Sasano, K. L. Parker, Mol. Endocrinol. 2000, 14, 1462 ; b) K. M. Caron, S. C. Soo, W. C. Wetsel, D. M. Stocco, B. J. Clark, K. L. Parker, Proc. Natl. Acad. Sci. USA 1997, 94, 11540.

[31] S. R. Bair, S. H. Mellon, Mol. Cell. Biol. 2004, 24, 5383.

[32] G. Delbes, C. Levacher, C. Duquenne, C. Racine, P. Pakarinen, R. Habert, Endocrinology 2005, 146, 2454.

[33] G. Delbes, C. Levacher, C. Pairault, C. Racine, C. Duquenne, A. Krust, R. Habert, Endocrinology 2004, 145, 3395.

[34] T. Haavisto, K. Nurmela, R. Pohjanvirta, H. Huuskonen, F. El-Gehani, J. Paranko, Mol. Cell Endocrinol. 2001, 178, 169.

[35] a) A. Nadal, P. Alonso-Magdalena, C. Ripoll, E. Fuentes, Pflugers Arch. 2005 , 449,335 ; b) A. Nadal, M. Diaz, M. A. Valverde, News Physiol. Sci. 2001, 16, 251; c) A. B. Ropero, P. Alonso-Magdalena, C. Ripoll, E. Fuentes, A. Nadal, J. Steroid. Biochem. Mol. Biol. 2006, 102, 163.

[36] P. Alonso-Magdalena, O. Laribi, A. B. Ropero, E. Fuentes, C. Ripoll, B. Soria, A. Nadal, Environ. Health Perspect. 2005 $113,969$.

[37] E. M. Szego, K. Barabas, J. Balog, N. Szilagyi, K. S. Korach, G. Juhasz, I. M. Abraham, J. Neurosci. 2006, 26, 4104.

[38] P. Mannella, R. D. Brinton, J. Neurosci. 2006, 26, 9439.

[39] J. L. Spearow, P. Doemeny, R. Sera, R. Leffler, M. Barkley, Science 1999, 285, 1259.

[40] a) S. C. Nagel, F. S. vom Saal, K. A. Thayer, M. G. Dhar, M. Boechler, W. V. Welshons, Environ. Health Perspect. 1997, 105, 70; b) F. S. vom Saal, P. S. Cooke, D. L. Buchanan, P. Palanza, K. A. Thayer, S. C. Nagel, S. Parmigiani, W. V. Welshons, Toxicol. Ind. Health 1998, 14, 239; c) F. S. vom Saal, B. G. Timms, M. M. Montano, P. Palanza, K. A. Thayer, S. C. Nagel, M. D. Dhar, V. K. Ganjam, S. Parmigiani, W. V. Welshons, Proc. Natl. Acad. Sci. USA 1997, 94, 2056.

[41] a) W. V. Welshons, S. C. Nagel, F. S. vom Saal, Endocrinology 2006, 147, S56; b) F. S. vom Saal, C. Hughes, Environ. Health Perspect. 2005, 113, 926.

[42] D. C. Dolinoy, J. R. Weidman, R. A. Waterland, R. L. Jirtle, Environ. Health Perspect. 2006, 114, 567.

[43] M. D. Anway, A. S. Cupp, M. Uzumcu, M. K. Skinner, Science 2005, 308, 1466. 